thấp. Tỉ lê KPCD thành công ở nhóm có tiền căn MLT hoặc đặt Foley lần 2 có thể có sự khác biệt nhưng những nhóm đối tượng này không thuộc mục tiêu nghiên cứu đặt ra. Cần thêm những nghiên cứu khác với thiết kế, phương pháp lây mẫu và cỡ mẫu phù hợp, bổ sung thêm các biến số như tiền căn MLT, KPCD bằng Foley lần 2; các yếu tố tương quan với $K P C D$ thành công và khả năng SNAD.

\section{TÀI LIÊU THAM KHẢO}

1. Nguyễn Thị Lâm Hà (2015), "Hiệu quả của khởi phát chuyển da bằng ông thống Foley đăt thông qua lố trong cố tử cung ở thai đû trưởng thành tai Bệnh viện Đa khoa Bà Rịa" Tạp chí Y học TPHCM, 20(1):322-327.

2. Ngố Minh Hưng (2019), "Hiệu quả khởi phát chuyển dạ với ống thông Foley đôi cải tiến trên thai kỳ quá ngày dư sinh có chỉ định chấm dứt thai kỳ tại Bệnh viện Nhân dân Gia Định", Tạp chí Y họ TPHCM, 23(2):121-126.

3. Nguyễn Bá Mỹ Ngoc (2013), "So sánh hiêu quả khởi phát chuyển dạ của Prostaglandin E2 và ông thông Foley ở thai 37 tuần thiếu ối", Tạp chí Y học TPHCM, 17(1):149-155.

4. Nguyến Thị Anh Phương (2016), "So sánh hiêu quả khởi phát chuyển da của thông Foley bóng đồ cải tiến và bóng đơn đặt kênh cố tử cung ở thai trưởng thành taai Bênh viện Hùng Vương", Tạp chí Y hoc TPHCM,20(1):316-321.

5. Lê Thị Hồng Vân (2014), "Hiệu quả ống thông Foley trong khởi phát chuyên da ở thai phụ có tiên căn mổ lây thai", Luận văn Bác sĩ nội trú ĐHYD TPHCM

6. Gary Cunningham (2018), "Induction and Augmentation of Labor", Williams Obstetrics 25th, Chapter 26.

7. Gary Cunningham (2018), "Physiology of Labor",Williams Obstetrics 25th, Chapter 21

8. Grobman W. A (2018), "Labor Induction versus Expectant Management in Low-Risk Nulliparous Women", N Engl J Med,379(6):513-523

\title{
ĐÁNH GIÁ HIỆU QUẢ CỦA VIÊN PHỐI HỢP LISINOPRIL VÀ AMLODIPIN TRONG ĐIỀU TRI TĂNG HUYẾT ÁP BẰNG MÁY ĐO VẬN TỐC SÓNG MẠCH VP PLUS 1000
}

\section{TÓM TẮT}

Mục đích: Đánh giá hiệu quả điều trị tăng huyết áp của viên phối hợp lisinopril và amlodipin bằng máy đo vận tốc sóng mạch. Đối tượng và phương pháp: 40 bệnh nhân tăng huyết áp nguyên phát tuổi trung bình $69,18 \pm 10,4$. Tất cả bệnh nhân được đo huyểt áp, vận tốc sóng mạch (baWPV), chỉ số ABI bằng máy đo vận tốc sóng mạch VP Plus 1000 trước khi vào điều trị. Sau đó tất cả bệnh nhân được dùng viên phối hợp Lisonorm (lisinopril $10 \mathrm{mg}$ và amlodipin $5 \mathrm{mg}$ ) trong 4 tuần. Sau 4 tuần bênh nhân được đo lại lần 2 cũng bằng máy đó vận tốc sóng mạch VP Plus 1000 . Kêt quả: Sau 4 tuẩn huyết áp tay phải giảm: 26,58 \pm $9,51 \mathrm{mmHg} / 8,6 \pm 4,47 \mathrm{mmHg}$; Huyết áp tay trái giảm: $26,88 \pm 11,27 / 13,55 \pm 8,15 \mathrm{mmHg} ;$ Huyết áp chân phải giảm: 23,75 $\pm 11,78 / 10,75 \pm 6,64 \mathrm{mmHg}$; Huyết áp chân trái giảm: $30,33 \pm 16,64 / 13,6 \pm 9,28 \mathrm{mmHg}$; Tỷ lệ đạt huyết áp mục tiêu là $72,5 \%$ (29/40 bệnh nhân). Vận tốc sóng mạch (baPWV) bên phải giảm: $593,65 \pm 416,59 \mathrm{~cm} / \mathrm{s}$; baPWV bên trái giảm: 585,4 \pm $447,19 \mathrm{~cm} / \mathrm{s}$. Kết luận: Viên phối hợp lisinopril 10mg và amlodipin $5 \mathrm{mg}$ có hiệu quả hạ huyết áp cả tứ chi và vân tốc sóng mạch, giảm độ cứng thành mạch khi đo bằng máy đo vận tốc sóng mạch VP Plus.

*Trường Đại họ Y khoa Vinh

Chịu trách nhiệm chính: Cao Trường Sinh

Email: caotruongsinh@gmail.com

Ngày nhận bài: 6.4.2021

Ngày phản biên khoa hoc: 25.5.2021

Ngày duyệt bài: 3.6.2021

\section{Cao Trường Sinh*, Hoàng Ngọc Linh*}

\section{SUMMARY}

TO EVALUATE THE EFFECT OF LISINOPRIL AND AMLODIPIN COMBINATION PILL IN THE TREATMENT OF HYPERTENSION BY METER THE PULSE WAVE VELOCITY VP PLUS 1000

Aim: To evaluate the antihypertensive effect of lisinopril and amlodipine combination pill by the meter of pulse wave velocity. Objects and methods: 40 patients with primary hypertension, mean age $69.18 \pm$ 10.4. All patients were measured blood pressure, pulse wave velocity (baWPV), ankle brachial index by the meter of pulse wave velocity VP Plus 1000 before entering treatment. All patients were then given the Lisonorm combination pill (lisinopril $10 \mathrm{mg}$ and amlodipine $5 \mathrm{mg}$ ) for 4 weeks. After 4 weeks, the patients was measured again with the same machine, the pulse wave velocity of VP Plus 1000. Results: After 4 weeks, right arm blood pressure decreased: $26.58 \pm 9.51 \mathrm{mmHg} / 8.6 \pm 4.47 \mathrm{mmHg}$; Left arm blood pressure decreased: $26.88 \pm 11.27 / 13.55 \pm$ $8.15 \mathrm{mmHg}$; Right ankle blood pressure decreased: $23.75 \pm 11.78 / 10.75 \pm 6.64 \mathrm{mmHg}$; Left ankle blood pressure decreased: $30.33 \pm 16.64 / 13.6 \pm$ $9.28 \mathrm{mmHg}$; The rate of patients with the target blood pressure was $72.5 \%$ (29/40 patients). Right baPWV decreased 593,65 $\pm 416,59 \mathrm{~cm} / \mathrm{s} ;$ Left baPWV decreased 585,4 $\pm 447,19 \mathrm{~cm} / \mathrm{s}$. Conclusion: The combination tablet of lisinopril $10 \mathrm{mg}$ and amlodipine $5 \mathrm{mg}$ effectively lowers blood pressure in both extremities and pulse wave velocity, and reduces vessel wall stiffness when measured by meter the pulse wave velocity VP Plus 1000. 


\section{I. ĐẶT VẤN ĐỀ}

Tăng huyết áp là một gánh nặng bệnh tật toàn cầu, là nguyên nhân chính gây tứ vong trên toàn thế giới, ước tính khoảng 10 triệu người tử vong vào năm 2015 [1]. Tỷ lệ đạt huyết áp mục tiêu chưa cao liên quan đến sử dụng thuốc và sự tuân thủ điều trị và các yếu tố nguy cơ [2].

Nhiều nghiên cứu cho thấy sử dụng viên phối hợp 2 thuốc làm tăng hiệu quả điều trị và ít tác dụng phụ hơn là tăng liều của một thuốc.

Trong thực hành lâm sàng, việc đánh giá hiệu quả tác dụng của thuốc chủ yếu là đang sử dụng máy đo huyết áp thường quy, một số trung tâm lớn thì áp dụng máy đo lưu động 24 giờ (ABPM). Hiện nay còn có phương tiện được sử dụng là máy đo vận tốc sóng mạch VP Plus, thiết bị này đo huyết áp tứ chi cùng một thời điểm, đo chỉ số cổ chân cánh tay và ghi vận tốc sóng mạch để đánh giá nguy cơ tim mạch và các bệnh động mạch ngoại biên. Để ứng dụng máy đo vận tốc sóng mạch trong đánh giá hiệu quả điều trị tăng huyết áp chúng tôi tiến hành đề tài: "Đánh giá hiệu quả điều trị của viên phối hợp lisinopril và amlodipin trong điều trị tăng huyêt áp bằng máy đo vận tốc sóng mạch VP Plus 1000".

II. Đốl TƯợNG VÀ PHƯƠNG PHÁP NGHIÊN CứU

2.1. Đối tượng nghiên cứu. 40 bệnh nhân,

18 nam, 22 nữ tuổi trung bình 69,18 $\pm 10,4$ được chẩn đoán tăng huyêtt áp nguyên phát điều trị nội trú và ngoại trú tại khoa Nội- Tim mạch Bệnh viện Trường Đại học $\mathrm{Y}$ khoa Vinh từ tháng 10/2020 đến tháng 5/2021.

\subsection{Phương pháp nghiên cứu}

Thiêt kế nghiên cứu: Thử nghiêm lâm sàng ngẫu nhiên đơn, tự chứng, đánh giá kết quả trước sau điều trị

Tất cả bệnh nhân được đo huyết áp ban đầu bằng máy huyết áp kế thủy ngân để chẩn đoán. Tiếp đến bệnh nhân được đo huyết áp tứ chi, vận tốc sóng mạch, chỉ số cổ chân cánh tay (ABI) bằng máy đo vận tốc sóng mạch VP Plus 1000 của hãng OMRON COLIN, Nhật Bản. Sau đó tất cả bệnh nhân được dùng thuốc viên phối hơp lisinopril $10 \mathrm{mg}$ và amlodipin $5 \mathrm{mg}$ ( Lisonorm 10/5mg) liều 1 viên/ngày, uống sau khi ăn sáng trong 4 tuần (28 ngày). Trong quá trình dùng thuốc bệnh nhân được theo dõ̃i, kiểm tra huyết áp bằng máy đo thủy ngân mỗi tuần 1 lần, đánh giá tác dụng phụ nếu có. Sau 28 ngày dùng thuốc bệnh nhân được đo huyết áp, vận tốc sóng mạch, chỉ số $A B I$ bằng máy đo vận tốc sóng mạch VP Plus lần 2 vào ngày thứ 29.

Kết quả được xử lý bằng phần mềm Excel và SPSS.

\section{KẾT QUẢ NGHIÊN CỨU}

3.1. Mức độ giảm HATT, HATTr, PP, MAP sau 4 tuân điêuu trị

Bảng 3.1 HATT, HATTr, PP, MAP tay phái trước và sau điều trị

\begin{tabular}{|c|c|c|c|c|c|}
\hline Biến số & Trước điều trị & Sau điều trị & Hiệu số HA & \% giảm & p (t-s) \\
\hline HATT & $160,8 \pm 16,2$ & $134,2 \pm 12,7$ & $26,58 \pm 9,51$ & $16,35 \pm 4,98$ & $\mathbf{p}<\mathbf{0 , 0 0 1}$ \\
\hline HATTr & $84,3 \pm 7,34$ & $75,7 \pm 6,48$ & $8,6 \pm 4,47$ & $10,07 \pm 4,94$ & $\mathbf{p}<\mathbf{0 , 0 0 1}$ \\
\hline PP & $75,5 \pm 12,04$ & $58,53 \pm 8,99$ & $17,98 \pm 7,81$ & $22,95 \pm 8,41$ & $\mathbf{p}<\mathbf{0 , 0 0 1}$ \\
\hline MAP & $109,78 \pm 9,6$ & $95,22 \pm 8,03$ & $14,58 \pm 5,4$ & $13,16 \pm 4,31$ & $\mathbf{p}<\mathbf{0 , 0 0 1}$ \\
\hline
\end{tabular}

$\mathrm{p}(\mathrm{t}-\mathrm{s})$ : Giá trị p trước sau điều trị

Các chỉ số HATT, HATTr, PP, MAP tay phải trước và sau điều trị giảm có ý nghĩa thống kê với p<0,001.

Bảng 3.2 HATT, HATTr, PP, MAP tay trái trước và sau điều trị

\begin{tabular}{|c|c|c|c|c|c|}
\hline Biến số & Trước điều trị & Sau điều trị & Hiệu số HA & \% giảm & p (t-s) \\
\hline HATT & $159,2 \pm 17,68$ & $132,32 \pm 15,04$ & $26,88 \pm 11,27$ & $16,71 \pm 6,26$ & $<\mathbf{0 , 0 0 1}$ \\
\hline HATTr & $88,72 \pm 11,03$ & $75,18 \pm 8,23$ & $13,55 \pm 8,15$ & $14,8 \pm 7,86$ & $<\mathbf{0 , 0 0 1}$ \\
\hline PP & $70,48 \pm 11.97$ & $57,15 \pm 12,74$ & $13,33 \pm 8,19$ & $18,82 \pm 11,21$ & $<\mathbf{0 , 0 0 1}$ \\
\hline MAP & $112,15 \pm 12.35$ & $94,25 \pm 9,47$ & $17,95 \pm 8,52$ & $15,7 \pm 6,45$ & $<\mathbf{0 , 0 0 1}$ \\
\hline
\end{tabular}

$\mathrm{p}(\mathrm{t}-\mathrm{s})$ : Giá trị p trước sau điêu trị

Các chỉ số HATT, HATTr, PP, MAP tay trái trước và sau điều trị giảm có ý nghĩa thống kê với $p<0,001$.

Bảng 3.3 HATT, HATTr, PP, MAP chân phải trước và sau điều trị

\begin{tabular}{|c|c|c|c|c|c|}
\hline Biến số & Trước điều trị & Sau điều trị & Hiệu số HA & \% giảm & p (t-s) \\
\hline HATT & $173,1 \pm 17,53$ & $149,35 \pm 16$ & $23,75 \pm 11,78$ & $13,56 \pm 6,1$ & $\mathbf{p}<\mathbf{0 , 0 0 1}$ \\
\hline HATTr & $85,85 \pm 7,78$ & $75,1 \pm 8,23$ & $10,75 \pm 6,64$ & $12,38 \pm 7,44$ & $\mathbf{p}<\mathbf{0 , 0 0 1}$ \\
\hline PP & $87,25 \pm 13,62$ & $74,25 \pm 12,54$ & $13 \pm 7,68$ & $14,7 \pm 7,9$ & $\mathbf{p}<\mathbf{0 , 0 0 1}$ \\
\hline MAP & $114,92 \pm 10,1$ & $99,93 \pm 9,75$ & $15,12 \pm 7,91$ & $13 \pm 6,35$ & $\mathbf{p}<\mathbf{0 , 0 0 1}$ \\
\hline
\end{tabular}

$\mathrm{p}(\mathrm{t}-\mathrm{s})$ : Giá trị p trước sau điều trị 
Các chỉ số HATT, HATTr, PP, MAP chân phải trước và sau điều trị có ý nghĩa thống kê với $\mathrm{p}$ $<0,001$. Các chỉ số HATT, HATTr, PP, MAP chân phải sau điêuu trị giảm.

Bảng 3.4. HATT, HATTr, PP, MAP chân trái trước và sau điều trị

\begin{tabular}{|c|c|c|c|c|c|}
\hline Biến số & Trước điều trị & Sau điều trị & Hiệu số HA & \% giảm & p (t-s) \\
\hline HATT & $177,62 \pm 20,95$ & $147,3 \pm 19,65$ & $30,33 \pm 16,64$ & $16,8 \pm 8,54$ & $\mathbf{p}<\mathbf{0 , 0 0 1}$ \\
\hline HATTr & $86,95 \pm 10,28$ & $73,35 \pm 9,34$ & $13,6 \pm 9,28$ & $15,22 \pm 9,41$ & $\mathbf{p}<\mathbf{0 , 0 0 1}$ \\
\hline PP & $90,68 \pm 17,41$ & $73,95 \pm 12,61$ & $16,73 \pm 12,9$ & $16,16 \pm 8,28$ & $\mathbf{p}<\mathbf{0 , 0 0 1}$ \\
\hline MAP & $117,2 \pm 12,18$ & $98 \pm 12,31$ & $19,17 \pm 10,62$ & $21,82 \pm 11,15$ & $\mathbf{p}<\mathbf{0 , 0 0 1}$ \\
\hline
\end{tabular}

$\mathrm{p}(\mathrm{t}-\mathrm{s})$ : Giá trị p trước sau điêu trị

Các chỉ số HATT, HATTr, PP, MAP chân trái trước và sau điều trị có ý nghĩa thống kê với $p<0,001$.

HATT, HATTr, PP, MAP chân trái sau điều trị giảm đáng kể.

3.2. Mức độ giảm vận tốc sóng mạch- baPWV sau 4 tuân điêuu trị

Bảng 3.5. Chi số baPWV trước và sau điều trị

\begin{tabular}{|c|c|c|c|c|c|}
\hline baPWV & Trước điêuu trị & Sau điều trị & Hiệu số HA & \%giảm & p (t-s) \\
\hline Bên phải & $2384,87 \pm 677,04$ & $1791,22 \pm 419,85$ & $593,65 \pm 416,59$ & $23,47 \pm 10,23$ & $\mathrm{p}<0,001$ \\
\hline Bên trái & $2405,78 \pm 717,96$ & $1820,38 \pm 446,28$ & $585,4 \pm 447,19$ & $22,71 \pm 11,56$ & $\mathrm{p}<0,001$ \\
\hline
\end{tabular}

$\mathrm{p}(\mathrm{t}-\mathrm{s})$ : Giá trị p trước sau điêu trị

Chỉ số baPWV bên phải, baPWV bên trái trước và sau điều trị giảm có ý nghĩa thống kê $p<0,001$.

3.3 Chỉ số ABI trước và sau điều trị

Bảng 3.6. Chỉ số ABI trước và sau điều trị

\begin{tabular}{|c|c|c|c|}
\hline ABI & Trước điều trị & Sau điêu trị & $\mathbf{p ~ ( t - s )}$ \\
\hline ABI bên phải & $1,08 \pm 0,09$ & $1,11 \pm 0,09$ & $\mathrm{p}=0,001$ \\
\hline ABI bên trái & $1,12 \pm 0,1$ & $1,11 \pm 0,08$ & $\mathrm{p}=0,023$ \\
\hline
\end{tabular}

Chỉ số $A B I$ bên phải, $A B I$ bên trái trước và sau điều trị có ý nghĩa thống kê $p<0,05$.

\section{BÀN LUÂN}

4.1 Mức độ giảm HATT, HATTr, PP, MAP sau 4 tuần điều trị bằng viên phối hợp Lisonorm. Nhiều thuốc hạ huyết áp có sẵn trên thị trường. Bất kỳ loại thuốc nào trong số này khi được sử dụng đơn lẻ như một liẹu pháp chỉ có hiệu quả ở 40\%-60\% bệnh nhân tăng huyết áp[4]. Một số nghiên cứu báo cáo của Dequattro V, Brouwer RML và công sự chỉ ra rằng điều trị phối hợp sử dụng thuốc hạ huyết áp thuộc hai nhóm khác nhau rất hữu ích và có triển vọng trong việc kiểm soát huyết áp ở bệnh nhân tăng huyết áp[4]. Trong số các cách phối hợp thuốc, thuốc ức chế hêe renin - angiotensin aldosterone (thuốc ức chế men chuyển, thuốc chẹn thụ thể angiotensin II) được khuyến cáo kết hợp với thuốc lợi tiểu hoăc thuốc chen kênh canxi. Sự kết hợp giữa thuốc ức chế men chuyển và thuốc chẹn kênh canxi tác dụng kéo dài cho phép kiểm soát huyết áp hiệu quả, bảo vệ cơ quan đích và giảm tỷ lệ biến cố tim mạch [ 5].

Trong nghiên cứu của chúng tôi sau quá trình điều trị viên phối hợp lisinopril và amlodipin trong 4 tuần các chỉ số huyết áp tâm thu, huyết áp tâm trương, huyết áp trung bình, áp lực mạch trước và sau đều giảm có ý nghĩa thống kê $(p<0,001)$. Tỷ lệ bệnh nhân đạt huyết áp mục tiêu chung $(<140 / 90 \mathrm{mmHg})$ là $72,5 \% \quad(29 / 40$ bệnh nhân).

Tay phải HATT trước điều trị là 160,8 \pm
$16,17 \mathrm{mmHg}$ sau 4 tuần giảm $26,58 \pm$ $9,51 \mathrm{mmHg}$ còn $134,22 \pm 12,74 \mathrm{mmHg}$ nghĩa là đã giảm được 16,35 $\pm 4,98 \%$. Giá trị HATTr trước điêu trị $84,3 \pm 7,34 \mathrm{mmHg}$ đã giảm 8,6 \pm 4,47 $\mathrm{mmHg}$ còn $75,7 \pm 6,48 \mathrm{mmHg}$. PP giảm $17,98 \pm$ $7,81 \%(17,98 \pm 7,81 \mathrm{mmHg})$.

Tay trái HATT trước điều trị là 159,2 $\pm 17,68$ $\mathrm{mmHg}$ sau 4 tuần giảm $26,88 \pm 11,27 \mathrm{mmHg}$ còn $132,32 \pm 15,04 \mathrm{mmHg}$ nghĩa là đã giảm được $16,71 \pm 6,26 \%$. Giá trị HATTr trước điều trị $88,72 \pm 11,03 \mathrm{mmHg}$ đã giảm $13,558,15 \mathrm{mmHg}$ còn $75,18 \pm 8,23 \mathrm{mmHg}$ với $\mathrm{p}<0,001$. PP giảm $13,33 \pm 8,19 \%(13,33 \pm 8,19 \mathrm{mmHg})$.

Chân phải HATT trước điều trị là $173,1 \pm$ $17,53 \mathrm{mmHg}$, sau điêu trị $149,35 \pm 16,03$, đã giảm $23,75 \pm 11,78 \mathrm{mmHg}(13,56 \pm 6,1 \%)$. HATTr $85,85 \pm 7,78$ giảm $10,75 \pm 6,64(12,38 \pm 7,44 \%)$ còn $75,1 \pm 8,23 \mathrm{mmHg}$. PP 87,25 $\pm 13,65$ giảm $13 \pm 7,68$ còn $74,25 \pm 12,54$. MAP trước điều trị là $114,92 \pm 10,07$ giảm $15,12 \pm 7,91$ sau điều trị 99,93 \pm 9,75.

Chân trái HATT trước điều trị là $177,62 \pm$ $20,95 \mathrm{mmHg}$, sau điêu trị $147,3 \pm 19.65 \mathrm{mmHg}$, đã giảm $30,33 \pm 16,64 \mathrm{mmHg}(16,8 \pm 8,54 \%)$. HATTr 86,95 \pm 10,28 mmHg giảm 13,6 $\pm 9,28$ $(15,22 \pm 9,41 \%)$ còn $73,35 \pm 9,34 \mathrm{mmHg}$. PP $90,68 \pm 17,41$ giảm $16,73 \pm 12,9$ còn $73,95 \pm$ 12,61 . MAP trước điều trị là $117,2 \pm 12,18$ giảm 19,17 $\pm 10,62$ sau điêu trị $98 \pm 12,31$.

Nghiên cứu của Phạm Chí Hiền và cộng sự 
năm 2015 đánh giá hiệu quả và an toàn của thuốc Lisonorm phối hợp cố định chứa $10 \mathrm{mg}$ lisinopril và $5 \mathrm{mg}$ amlodipine trên bệnh nhân tăng huyết áp tại bệnh viện An Giang trên 183 bệnh nhân theo dõi trong 8 tuần với 3 lần thăm khám. Trong lần đầu thăm khám có 22 bệnh nhân chưa đạt huyết áp bình thường khi thu nhận với HATT trung bình là $148,2 \pm 10,5$ giảm $22,7 \mathrm{mmHg}$ còn $125,5 \pm 8,0$; HATTr trung bình là $89,1 \pm 8,1$ giảm 8,6 còn $79,1 \pm 5,3$ với $p<0,001$ sau điều trị 4 tháng số bệnh nhân đạt mục tiêu là 92,2\%.[3]

Nghiên cứu của MUR Naidu và cộng sự năm 2000 cho thấy sự giảm đáng kể HATT và HATTr sau 4 tuần điều trị viên kết hợp Lisinopril và Amlodipin là $\mathrm{HA}$ khi nằm $149 / 98 \mathrm{mmHg}$ giảm xuống $127 / 79 \mathrm{mmH}$, mức giảm có ý nghĩa thống kê $(p<0,001)$, sau quá trình điều trị có đến $71 \%$ bệnh nhân đạt huyết áp mục tiêu [7]. Theo Attila Ko'nyi năm 2016 nghiên cứu trên 2241 bệnh nhân HATT/HATTr 159,9 \pm 13,3/90,0 \pm 8,6 sau 1 tháng điều trị viên phối hợp Lisinopril + Amlodipin lần lượt là 136,9 $\pm 10,09 / 81,5 \pm 6,9$ với $p<0,05$, và số bệnh nhân đạt huyết áp mục tiêu sau 3 tháng $68 \%$, sau 6 tháng $91 \%$. Nghiển cứu của Semagina và cộng sự về hiệu quả kết hợp viên lisinopril và amlodipine ở bệnh nhân tăng huyết áp và gan nhiễm mõ không do rượu sau 12 tuần, $\mathrm{HA}$ tại phòng khám là 134,5 \pm 8,4/ $85,6 \pm 7,6, \mathrm{HA}$ cánh tay sau 24 giờ giảm từ $143,5 \pm 6,2 / 89,2 \pm 5,4$ xuống 132,3 $\pm 5,8 / 80,8 \pm$ 4,6 , ban ngày từ $144,4 \pm 7,0 / 92,1 \pm 5,3$ đến $134,5 \pm 6,6 / 83,7 \pm 6,1$, ban đêm từ $132,3 \pm$ $6,6 / 79,1 \pm 5,9$ đến $117,6 \pm 5,2 / 69,4 \pm 5,0 \mathrm{mmHg}$ (với mọi $p<0,05$ )[6].

Nghiên cứu của Vinay. K.Bahl về điều trị tăng huyết áp với liều cố định perindopril và amlodipine $(4 \mathrm{mg} / 5 \mathrm{mg})$ 1lần/ngày trong 60 ngày. Tổng cộng có 1250 bệnh nhân nghiên cứu bao gồm: $32,6 \%$ bị tăng huyết áp mới được chẩn đoán; $40,5 \%$ bị tăng huyết áp không kiểm soát được bằng đơn tri liệu; và $26,9 \%$ tăng huyết áp được quản lý không đây đủ bằng một liệu pháp kêt hợp khác. HATT/HATTr trung bình giảm đáng kể so với ban đâu $(167,4 \pm 15,2 / 101,4 \pm$ $9,1 \mathrm{mmHg})$ trong 60 ngày $(-41,9 \pm 34,8 /-23,2$ $\pm 21,8 \mathrm{mmHg} ; \mathrm{p}<0,0001)$. HA mục tiêu đạt được ở $66,1 \%$ bệnh nhân trong tổng dân số, $68,3 \%$ bênh nhân không được điêu trị, 68,4\% bệnh nhân không kiểm soát được bằng liệu pháp đơn trị liệu và $59,9 \%$ bệnh nhẩn được quản lý không tốt với liệu pháp phối hợp. Ở 161 bệnh nhân có HATT >180mmHg lúc ban đầu (mới chẩn đoán: $\mathrm{n}=50$; không kiểm soát được khi điều trị đơn trị: $n=53$; quản lý không đầy đủ khi điều trị phối hợp: $n=58)$, HA đã giảm 63,2 \pm 32,5/ $29,0 \pm 21,9 \mathrm{mmHg}(p<0,0001)$ ở ngày thứ 60 . Sự kết hợp thuốc viên cố định là an toàn và dung nap tốt. Tất cả 1175 bệnh nhân hoàn thành nghiên cứu 60 ngày (94\%) đều tuân thủ chế độ điêu trị của họ.[4]

Tại thời điểm thu nhận bệnh nhân, hầu hết bệnh nhân của chúng tôi đã được điều trị huyết áp trước đó nhưng chưa đạt mục tiêu điều trị nên việc giảm và đạt huyểt áp mục tiêu lâm sàng là cần thiết. Sau quá trình nghiên cứu việc kiểm soát huyết áp hiệu quả có thể đạt được sau khi điêu tri viên phối hợp Lisinopril và amlodipin. Nghiên cứu đã chỉ ra rẳng việc phối hợp lisinopril và amlodipine giảm HATT, HATTr có ý nghĩa và tỷ lệ đạt được huyết áp mục tiêu là khá cao $(72,5 \%)$. Sau khi điêu trị 1 tháng đã cải thiên đáng kể về kiểm soát huyết áp, đáp ứng huyết áp trung bình, áp lực mạch.

4.2 Mức độ giảm của vận tốc sóng machbaPWV. Chỉ số baPWV bên phải trước điêu trị là $2384,87 \pm 677,04 \mathrm{~cm} / \mathrm{s}$ giảm 593,65 $\pm 416,59$ $(23,47 \pm 10,23 \%)$ sau điều trị còn $1791,22 \pm$ 419,85 với $p<0,001$. Chỉ số baPWV bên trái trước điêu trị là $2405,78 \pm 717,96 \mathrm{~cm} / \mathrm{s}$ sau 1 tháng điêu trị còn $1820,38 \pm 446,28 \mathrm{~cm} / \mathrm{s}$ đã giảm $585,4 \pm 447,19(22,71 \pm 11,56 \%)$ với $p<0,001$.

Cũng theo nghiên cứu của Tetsuya Ichiharra và công sư năm 2005 về việc sử dụng ức chế thụ thể angiotensin là valsartan làm giảm độ cứng động mạch độc lập với hạ huyết áp ở bệnh nhân THA sau 24 tuần điều trị thì sự giảm giá trị của baPWV $1.794 \pm 46 \mathrm{~cm} / \mathrm{s}$ trước khi valsartan ( $\mathrm{n}=39)$ vs. $1,663 \pm 45 \mathrm{~cm} / \mathrm{s}$ sau khi dùng valsartan $(p=0,048, n=31)$ có ý nghĩa thống kê $p<0,05$ và ở mức HATT trung bình tương tự (149 \pm 2 so với $146 \pm 3 \mathrm{mmHg}, \mathrm{p}=0,304)$.

Theo kết quả nghiên cứu có thể thấy bên cạnh việc hạ áp hiệu quả thì quá trình điều trị viên phối hợp lisinopril và amlodipine cũng giúp giảm đáng kể chỉ số baPWV. Điều này đặc biệt quan trọng vì những nghiên cứu trước đây đã chỉ ra rằng chỉ số baPWV là một yếu tố độc lập dự đoán nguy cơ tim mạch, dự đoán tiên lượng tử vong ở những bệnh nhân tẳng huyết áp. Do đó, baPWV có thể sử dụng để đánh giá mức độ bảo vệ thành mạch trong thời gian điều trị huyết áp.

4.3 Mức độ giảm chỉ số ABI. Về vấn đề này, nghiên cứu của Cao Trường Sinh về đánh giá chỉ số cổ chân- cánh tay ở bệnh nhân tăng huyết áp bằng máy đo vận tốc sóng mạch VP 1000 Plus gồm 96 bệnh nhân THA nguyên phát chưa được dùng thuốc hạ huyết áp tại phòng khám đa khoa trường Đại học Y khoa Vinh. Kết 
quả thấy rằng $A B I$ trung bình bên phải ở bênh nhân THA là $1,008 \pm 0,146$, bên trái là $0,989 \pm$ 0,118 , bên phải cao hơn bên trái 0.019 . Tỷ lệ $A B I \leq 0,09$ (tỷ lệ PAD) ở bệnh nhân THA nguyên phát là $38,5 \%$, trong đó 1 bên là $22,9 \%$, cả 2 bên là $15,6 \%$. Tỷ lệ PAD ở độ tuổi $>70$ là cao nhất [8]. Trong nghiên cứu của chúng tôi trước điều trị bệnh nhân có $A B I$ bên phải $1,08 \pm 0,09$, bên trái $1,12 \pm 0,1$ và nhóm nghiên cứu không có bệnh nhân có chỉ số $A B I<0,9$ và $A B I>1,3$.

Nghiên cứu của Deirdre A Lane, Gregory YH Lip năm 2013 về việc điều trị tăng huyết áp ở bênh nhân mắc bệnh động mạch ngoại biên trên 3610 bệnh nhân. Bốn nghiên cứu so sánh một nhóm điều trị chống tăng huyết áp được công nhận với giả dược và bốn nghiên cứu so sánh hai phương pháp điều trị chống tăng huyết áp với nhau. Các nghiên cứu không được gộp chung do sự thay đổi của các so sánh và kết quả được trình bày và kết qủa cho thấy chưa thể đủ bằng chứng về lợi ích của thuốc điêuu trị THA lên bệnh nhân mắc bệnh động mạch ngoại biên. [9]

Nghiên cứu của chúng tôi, có sự liên quan giữa chỉ số $A B I$ trước và sau điêu trị với $p<0,01$. Vì số bệnh nhân trong nhóm có ABI đều bình thường nên chưa thể đánh giá được liệu viên phối hợp lisinopril và amlodipine có thực sự thay đổi có ý nghĩa ở nhóm bệnh nhân có $A B I$ bất thường hay không. Tuy nhiên, việc thiếu dữ kiện cũng không nên làm giảm đi tác dụng áp đảo về lợi ích điều trị THA và hạ áp, và viên phối hợp lisinopril và amlodipine thực sự có tác dụng hạ áp hiệu quả.

\section{KẾT LUÂNN}

Viên phối hợp lisinopril $10 \mathrm{mg}$ và amlodipine $5 \mathrm{mg}$ (Lisonorm $10 / 5 \mathrm{mg}$ ) có hiệu quả giảm huyết áp tứ chi và vận tốc sóng mạch, độ cứng động mạch ở bệnh nhân tăng huyết áp nguyên phát khi đo bằng máy đo vận tốc sóng mạch VP Plus.

\section{TÀI LIÊU THAM KHẢO}

1. Forouzanfar M.H. et al.(2017), "Global Burden of Hypertension and Systolic Blood Pressure of at Least 110 to $115 \mathrm{mmHg}, 1990-2015^{\prime \prime}$, The Journal of the American Medical Association, 317(2): 165-182.

2. Huỳnh Văn Minh, Nguyến Lân Việt (2020), "Asian management of hypertension: Current status, home blood pressure, and specific concerns in Viet Nam, Journal Clinical Hypertension 2020:22:519-521.

3. Phạm Chí Hiền; Nguyễn Thiện Tuấn; Sử Cẩm Thú (2015)," Đánh giá hiệu quả và an toàn của thuốc LISONORM phối hợp cố định chứa $10 \mathrm{mg}$ LISINOPRIL và $5 \mathrm{mg}$ AMLODIPIN trên bênh nhân THA tai An Giang", Báo cáo khoa họ Bệnh viện Đa khoa Än Giang 2015, tr.44-53.

4. Vinay.K.Balt, et al.(2012), "Management of hypertension with the fixed combination of perindopril and amlodipine in daily clinical practice", American Journal of Cardiovascular Drugs 9, 135-142.

5. Mur Naidu, PR Usha, TRamesh Kumar Rao, JC Shobha (2000), "Evaluation of amlodipine, lisinopril, and a combination in the treatment of essential hypertension", Postgrad Med J., 76(896): 350-353.

6. Semagina, I.; Kotovskaya, Y.; Kobalava. (2015), "Effects of Lisinopril/ amlodipine single pill combination on ambulatory brachial and central blood pressure in hypertensive subjects with nonalcoholic fatty liver diese", Journal of Hypertension, Vol33:p199.

7. Tetsuya Ichihara, et al.(2005), "Selective angiotensin receptor antagonism with valsartan decreases arterial stiffness independently of blooad pressure lowering in hypertensive patients", Hyperten Res. 28 (12):937-43.

8. Cao Trường Sinh (2015), "Nghiên cứu chỉ số cổ chân-cánh tay ở bệnh nhân tăng huyết áp nguyên phát", Tap chí Y học thực hành, số 971 (7/2015), tr 54-57.

9. Deirdre A Lane, Gregory YH Lip, (2013) "Treatment of hypertension in peripheral arterial disease", Cochrane Database Syst Rev, 7:3075.

\title{
MỐI LIÊN QUAN GIỮA BIẾN CHỨNG VẬN ĐộNG VÀ TÌNH TRANG CHẬM LÀM TRỐNG DẠ DÀY TRONG BỆNH PARKINSON
}

\author{
Trần Thanh Hùng*, Vũ Anh Nhị*, Nguyễn Xuân Cảnh**
}

TÓM TẮT

\footnotetext{
*Đại học Y dược Thành phố Hồ Chí Minh, **Bêenh viện Chơ Rẫy.

Chịu trách nhiệm chính: Trân Thanh Hùng Email: tranthanhhungmd@ump.edu.vn Ngày nhận bài: 2.4.2021

Ngày phản biên khoa học: 25.5 .2021

Ngày duyệt bài: 4.6.2021
}

Mở đâu: Bệnh Parkinson là bệnh thoái hóa thần kinh thường găp đứng hàng thứ hai sau bênh Alzheimer. Chậm làm trống dạ dày có thể là cơ chế dược động hợ quan trong gây ra các biến chứng vân động của bệnh Parkinson. Mục tiêu nghiên cứu: khảo sát mối liên quan giữa biến chứng vận động và tình trạng chậm làm trống dạ dày trong bệnh Parkinson. Phương pháp nghiên cứu: nghiên cứu cắt ngang mô tả, tiến cứu trên bệnh nhân mắc bệnh Parkinson và ký đồng ý tham gia nghiên cứu. Bệnh nhân được đánh giá các biến chứng vận động và được 